\title{
Identification of an HLA-A*020 I-restricted T-cell epitope derived from the prostate cancer-associated protein prostein
}

\author{
A Kiessling', S Stevanovic ${ }^{2}$, S Füssel ${ }^{3}$, B Weigle', MA Rieger', A Temme', EP Rieber' and M Schmitz*,I \\ IInstitute of Immunology, Medical Faculty, Technical University of Dresden, Fetscherstr. 74, Dresden 01307, Germany; ${ }^{2}$ Department of Immunology, \\ Institute for Cell Biology, University of Tübingen, Auf der Morgenstelle 15, Tübingen 72076, Germany; ${ }^{3}$ Department of Urology, Medical Faculty, Technical \\ University of Dresden, Fetscherstr. 74, Dresden 01307, Germany
}

\begin{abstract}
The development of T-cell-based immunotherapies of cancer largely depends on the availability of tumour-associated antigens capable of eliciting tumour-directed cytotoxic T-cell responses. In prostate cancer, the number of antigens defined as suitable targets of cytotoxic T lymphocytes (CTLs) is still limited. Recently, prostein was identified as a transmembrane protein that is highly restricted to prostate tissues. In our study, prostein transcripts were found to be abundant in both malignant and nonmalignant prostate tissue samples. To identify immunogenic CD8 + T-cell epitopes, human leucocyte antigen-A*020I-binding peptides were selected from the amino-acid sequence of prostein and were used for the in vitro stimulation of CD8 + T lymphocytes. Specific CTLs were raised against the prostein-derived peptide CLAAGITYV that were capable of lysing prostate cancer cells, indicating that this peptide is naturally generated by tumour cells. Our data suggest that prostein is a suitable candidate to be included in a T-cell-based immunotherapy of prostate cancer.

British Journal of Cancer (2004) 90, 1034- 1040. doi:I0.1038/sj.bjc.660 I642 www.bjcancer.com
\end{abstract}

(c) 2004 Cancer Research UK

Keywords: prostein; T cells; tumour antigen; dendritic cells; immunotherapy

Prostate carcinoma (PCa) is the most common cancer diagnosis and the second leading cause of cancer-related deaths in men (Howe et al, 2001). The absence of effective curative therapies for advanced and recurrent prostate tumours has entailed an intensive search for novel treatment modalities.

$\mathrm{T}$ cells provide a powerful compartment of adaptive immunity with the potential to survey and respond to a great diversity of antigens. The immunotherapy of human tumours has been put forward by the finding that $\mathrm{CD} 8+$ cytotoxic $\mathrm{T}$ lymphocytes (CTLs) are capable of effective recognition and destruction of tumour cells (Rosenberg, 1997). Consequently, much attention has been paid to the identification and characterisation of tumourassociated antigens (TAAs) that may provide target structures for a T-cell-based vaccination strategy (Saffran et al, 1999; Nelson, 2002).

While searching for new potential immunotherapeutic targets of $\mathrm{PCa}$, a number of prostate- or $\mathrm{PCa}$-associated transcripts and proteins have been identified during the last years such as sixtransmembrane epithelial antigen of the prostate (Hubert et al, 1999), prostase (Nelson et al, 1999), prostate androgen-regulated transcript 1 (PART-1) (Lin et al, 2000), human novel prostatespecific antigen (PSA) (Naz et al, 2002), human prostate-specific gene-1 (Herness and Naz, 2003) and NKX3.1 (He et al, 1997). However, recent observations suggest that the expression of some of these molecules is not strictly confined to prostate tissue (Hubert et al, 1999; Yousef et al, 1999; Sidiropoulus et al, 2001). The suitability of these molecules for T-cell-based immunotherapy is limited, since targeting epitopes that are presented on essential

*Correspondence: M Schmitz; E-mail: mschmitz@rcs.urz.tu-dresden.de Received 20 May 2003; revised 5 December 2003; accepted 15 December 2003 tissues may induce adverse autoimmune reactions. Other molecules are downregulated in tumour tissue when compared with normal prostate tissue (Bowen et al, 2000; Xu et al, 2003).

The high diversity, the genetic instability and the escape mechanisms of tumours determine the number of individual target structures for T-cell-based immunotherapeutic strategies. In addition, the number of prostate-specific proteins known to elicit $\mathrm{T}$-cell responses is still limited. Therefore, the identification of new TAAs can facilitate T-cell-based vaccination strategies in $\mathrm{PCa}$ patients. The efficiency of the antitumour response could be increased by including a collection of well-characterised epitopes derived from diverse antigens for the activation of patients' $\mathrm{T}$ cells.

Recently, prostein was identified as a novel prostate-specific protein using a cDNA library substraction strategy (Xu et al, 2001). The expression of prostein is highly restricted to malignant and nonmalignant prostate tissues at both mRNA and protein level.

Having confirmed the expression of prostein in normal and malignant prostate tissues by real-time PCR, we investigated the suitability of prostein to serve as a target antigen for PCa-directed CTLs. An immunogenic human leucocyte antigen (HLA)- $A^{\star} 0201-$ restricted peptide derived from prostein was identified, which proved to be effective in activating tumour-directed CTL responses. The newly identified peptide may be appropriate to be included as a target structure in a T-cell-based immunotherapy of patients with HLA-A*0201-positive PCa.

\section{MATERIAL AND METHODS}

\section{Cell lines}

The PCa cell lines LNCaP 1740 and PC-3, the mutant cell line T2 and the chronic myelogenous leukemia cell line K562 (all from 
American Type Culture Collection, Manassas, VA, USA) were cultured according to the manufacturer's instructions. The melanoma cell line 93.04A12.1 was kindly provided by Dr CJM Melief (University Hospital, Leiden, The Netherlands). This cell line was maintained in RPMI 1640 medium (Biochrom, Berlin, Germany) supplemented with $2 \mathrm{~mm}$ L-glutamine, $1 \%$ nonessential amino acids (both from Biochrom), $100 \mu \mathrm{g} \mathrm{ml}^{-1}$ penicillin, $100 \mu \mathrm{g} \mathrm{ml}^{-1}$ streptomycin (both from Life Technologies, Karlsruhe, Germany) and $10 \%$ heat inactivated foetal calf serum (FCS) (Biochrom).

The androgen deprivation and stimulation experiments were performed as described previously (Xu et al, 2001). Briefly, LNCaP 1740 cells were cultured for $24 \mathrm{~h}$ in phenol red-free RPMI (Life Technologies) supplemented with $1 \%$ nonessential amino acids, 10 mM HEPES (Life Technologies) and 10\% charcoal-stripped FCS (Biochrom). The cultivation was continued for additional $48 \mathrm{~h}$ in the androgen-depleted medium or in the presence of $1 \mathrm{~nm}$ of the synthetic androgen R1881 (Perkin-Elmer Life Sciences, RodgauJügesheim, Germany). Subsequently, the cells were harvested and were used as target cells in a chromium release assay.

\section{Prostate cancer patients and tissue samples}

All tissue and blood samples were obtained from prostatectomised PCa patients and healthy donors with informed consent. All samples from PCa patients were obtained together with clinical data and pathological classification (Table 1). We analysed pairs of tissue samples (specimens of primary $\mathrm{PCa}$ and autologous nonmalignant prostate tissue) from 15 patients.

\section{RNA isolation and cDNA synthesis}

Total RNA was extracted by standard procedures (Trizol LS Reagent; Life Technologies, Karlsruhe, Germany) and quality was analysed by agarose-gel electrophoresis. After DNA digestion (DNase I; Amersham Pharmacia Biotech, Freiburg, Germany), cDNA synthesis was performed using $4 \mu \mathrm{g}$ of total RNA and random hexamer primers (Ready to Go You Prime First Strand Kit; Amersham Pharmacia Freiburg Biotech, Germany).

\section{Quantitative reverse transcription (RT) - PCR}

The mRNA quantity of prostein was determined using a LightCycler (LC)-based real-time PCR protocol based on SYBR Green I detection (LC - FastStart DNA Master SYBR Green I; Roche Diagnostics, Mannheim, Germany) and the primer pair Prostein_N1 (5'-AACCTTTGGCCTGGAGGTGTGTTTG-3') and Prostein_C1 ( $5^{\prime}$-GGGATGAGAAAGAGGCTCAGCAGGA-3') to amplify a $240 \mathrm{bp}$ cDNA fragment spanning two exons.

The mRNA copy number was adjusted to the RT - PCR product quantity of hypoxanthine phosphoribosyltransferase (HPRT) determined by LC technique using the primer pair HPRT_N1 $\left(5^{\prime}\right.$-CCCTGGCGTCGTGATTAGTGATGAT- $\left.3^{\prime}\right)$ and HPRT_C1 $\left(5^{\prime}-\right.$ TGCTTTGATGTAATCCAGCAGGTCAGC- $3^{\prime}$ ) for the amplification of a 238 bp fragment.

Serial dilutions of plasmid DNA containing the prostein or HPRT fragments over six log scales $\left(10^{1}-10^{6}\right.$ molecules capillary ${ }^{-1}$ ), allowing the linear regression of the crossing points $v s$ the logarithm of sample concentration (regression coefficient: -1.00 ; mean squared error: $<0.15)$, were used as internal template standards for the calculation of the transcript copy number (calculation via fit point mode of the LC quantification software version 3.5; Roche Diagnostics, Mannheim, Germany). The detection limit of the assays was 10 transcript copies. Each determination was carried out twice for each cDNA sample. From the mean values, the molecule ratios of prostein to HPRT transcripts were calculated.

\section{Epitope prediction and peptide synthesis}

Potential HLA-A ${ }^{\star} 0201$ ligands were selected from the amino-acid sequence of prostein (accession no. NP_149093) using a matrix pattern suitable for the calculation of peptides fitting to an HLA$\mathrm{A}^{\star} 0201$ motif (Rammensee et al, 1999; http://www.syfpeithi.de). This scoring system allows the prediction of the binding affinity of a given peptide to HLA- $A^{*} 0201$ by evaluating each amino acid within the sequence for their preference in the respective position. The allocation of values is based on the frequency of the respective amino acid in known natural ligands, T-cell epitopes or binding peptides. The six highest scoring peptides were synthesised as described previously (Kiessling et al, 2002).

\section{Competition assay}

Binding studies of potential HLA-A ${ }^{*} 0201$ fitting peptides were carried out using the B-cell lines LCL721 or JY and a fluorescencebased competition assay, essentially as described by van der Burg et al (1995), but without performing acid strip. Reporter peptide

Table I Pathological and clinical parameters (UICC TNM classification system from 1997) and the percentage of tumour cells in tissue samples analysed by real-time PCR

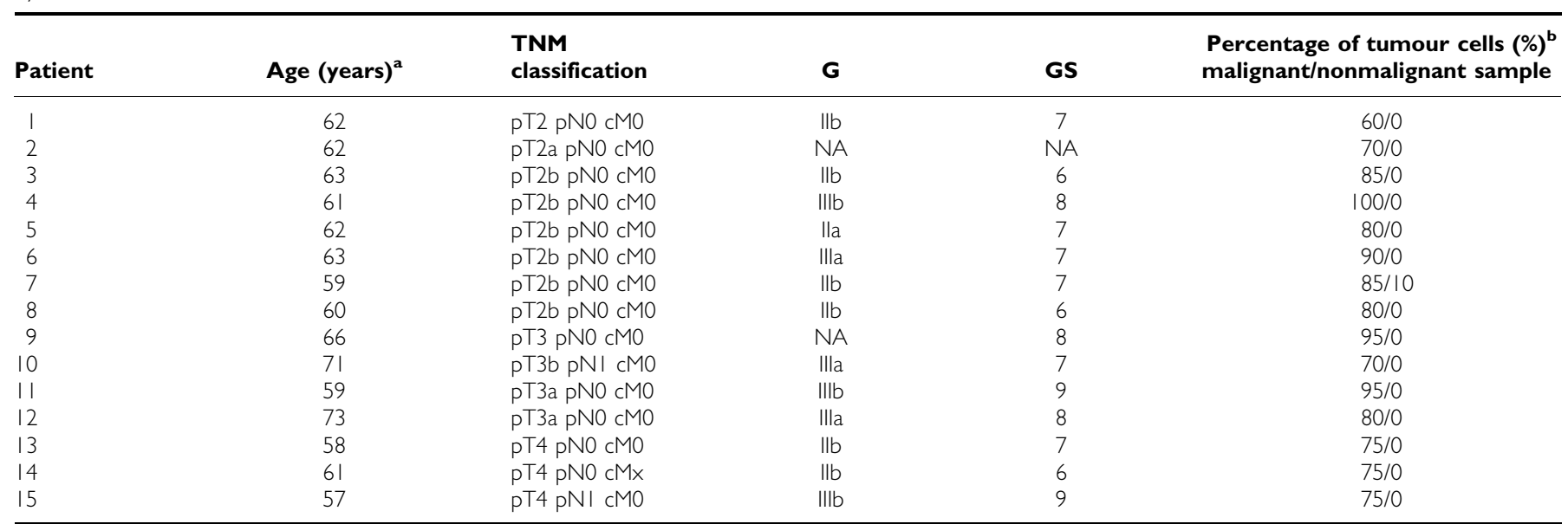

${ }^{a}$ At the time point of prostatectomy. ${ }^{b}$ Percentage of tumour cells within the epithelial cells. G, tumour grade; GS, Gleason score; N, lymph node metastases; NA, not available; p, pathological examination; T, tumour stage. 
was ILK(FITC)EPVHGV from HIV-1 reverse transcriptase and positive control was YLLPAIVHI from RNA helicase p72. Fluorescence intensities were recorded by flow cytometry (FACSCALIBUR; Becton Dickinson, Heidelberg, Germany).

\section{In vitro generation of prostein-specific CD8 + cytotoxic $\mathrm{T}$ lymphocytes}

Briefly, peripheral blood mononuclear cells were prepared from blood samples by Ficoll-Hypaque (Biochrom) density centrifugation. Monocytes were isolated by immunomagnetic cell separation with an anti-CD14 antibody coupled to paramagnetic microbeads (Miltenyi Biotech, Bergisch Gladbach, Germany) according to the manufacturer's instructions. Mature monocyte-derived dendritic cells (DCs) were generated as described previously (Schmitz et al, 2000).

To generate prostein-specific CTLs, mature DCs were either pulsed with a cocktail of the prostein-derived peptides 1478,1479 and 2004 or a cocktail of the peptides 1472,1487 and 1494 at a concentration of $20 \mu \mathrm{g} \mathrm{ml}^{-1}$ of each peptide in serum-free RPMI 1640 medium for $3 \mathrm{~h}$. After washing $2 \times 10^{5}$ peptide-loaded DCs were cocultured with $2 \times 10^{6}$ immunomagnetically isolated CD8 + $\mathrm{T}$ cells well ${ }^{-1}$ of a 24 -well tissue culture plate (Greiner, Frickenhausen, Germany). T-cell cultures stimulated with DCs pulsed with the peptides 1478, 1479 and 2004 were established from two prostate cancer patients (donors 1 and 3 ) and a healthy individual (donor 2). The peptides 1472, 1487 and 1494 were used to stimulate an additional culture of donor 2 and T cells obtained from another patient (donor 4). The T cells were cultured in $2 \mathrm{ml}$ RPMI 1640 medium well ${ }^{-1}$ supplemented with $10 \%$ human serum (CCpro, Neustadt, Germany), $100 \mathrm{U} \mathrm{ml}^{-1}$ IL-2 and $10 \mathrm{ng} \mathrm{ml}^{-1}$ IL-7 (both from Strathmann Biotech, Hanover, Germany). After 7 days, cultures were washed and restimulated with peptide-loaded DCs at a responder to stimulator ratio of $5: 1$. After three rounds of weekly restimulation, the cultures were tested for the presence of prostein-specific CTLs.

\section{Chromium release assay}

Cytotoxic activity of the in vitro-stimulated CTLs was assayed against the HLA-A*0201-positive mutant cell line T2 pulsed with the individual prostein-derived peptides or an irrelevant HLA$\mathrm{A}^{*} 0201$-binding peptide from HIV-1 reverse transcriptase at a concentration of $50 \mu \mathrm{g} \mathrm{ml}^{-1}$, against the PCa cell line LNCaP 1740, the melanoma cell line 93.04A12.1 and against K562 cells as targets in a $4 \mathrm{~h}$ standard ${ }^{51} \mathrm{Cr}$ release assay as described previously (Kiessling et al, 2002). The HLA-A2 restriction of CD8 + T-cellmediated lysis was tested at an effector cell to target cell ratio of $30: 1$ in the presence of the anti-HLA-A2 monoclonal antibody derived from the MA2.1 hybridoma (American Type Culture Collection) at a final concentration of $1 \mu \mathrm{g} \mathrm{ml}^{-1}$.

\section{Flow cytometry}

To evaluate the expression of HLA-A2 on the tumour cell lines used as target cells in the chromium release assays, LNCaP 1740 cells and the melanoma cell line 93.04A12.1 were harvested and resuspended in FACS buffer (phosphate-buffered saline $+0.05 \%$ sodium acid). Thereafter, the cells were incubated with the antiHLA-A2 monoclonal antibody MA2.1 or an isotype-matched control antibody (Mouse IgG1; BD Pharmingen, San Diego, CA, USA) both at a concentration of $10 \mu \mathrm{g} \mathrm{ml}^{-1}$ and stained with a PElabelled goat anti-mouse IgG $\mathrm{F}\left(\mathrm{ab}^{\prime}\right)_{2}$ fragment (Beckman Coulter, Krefeld, Germany), followed by flow cytometric analysis. To verify the specificity of MA2.1, the HLA-A2-negative PCa cell line PC-3 was included in the FACS analysis (Figure $3 \mathrm{C}$ ).

\section{RESULTS}

\section{Quantitative assessment of prostein mRNA expression in prostate tissue specimens}

Paired malignant and nonmalignant prostate tissue specimens obtained from 15 patients with histologically confirmed PCa were analysed for prostein expression using the quantitative RT - PCR. The pathological and clinical parameters as well as the percentage of tumour cells in the individual samples as determined histologically are summarised in Table 1. As depicted in Figure 1, prostein mRNA was detected in all tested normal prostate tissue samples, in the corresponding tumours with different degrees of progression and in the PCa cell line LNCaP. The expression level of prostein was highly variable among the patients. In 13 out of 15 patients, prostein transcripts were found at higher or similar levels in the tumour samples when compared with the corresponding nonmalignant tissues (Figure 1A), demonstrating that prostein expression is maintained or even upregulated in the great majority of tumourous tissues. The mean value of all ratios of prostein expression in the tumourous tissue to that in the corresponding nontumourous tissue (T/NT ratio) was 1.82 . When the samples were classified according to the pathological stage and grade, we found higher mean T/NT ratios in tumours of early stages and lower grades (Table 2). Owing to the high variability among the $\mathrm{T} /$ NT ratios of the individual samples with the same pathological features and a similar percentage of tumour cells, this correlation was not statistically significant (unpaired Student's $t$-test). Furthermore, no correlation between the Gleason score of the tumours and the T/NT ratios was determined (Table 2).

Following the observation by $\mathrm{Xu}$ et al (2001) that prostein expression is regulated by androgens, the androgen-responsive PCa cell line LNCaP 1740 was grown in medium containing FCS that was depleted of androgens by charcoal stripping or in the same stripped medium supplemented with the synthetic androgen $\mathrm{R} 1881$ and then used for the quantification of prostein transcripts. As depicted in Figure 1B, the prostein mRNA expression was downregulated but still detectable under conditions of androgen deprivation when compared with LNCaP cells cultured in the presence of R1881.

\section{Selection of HLA-A ${ }^{\star} 0201-$ binding peptides}

Using a suited algorithm, the amino-acid sequence of prostein was screened for peptides predicted to bind to HLA-A*0201, the most common HLA class I allele in Caucasian individuals (Table 3). Peptides that effectively bind to HLA-A ${ }^{\star} 0201$ are usually nonamers or decamers with the typical anchor position isoleucine (I) or leucine (L) at position 2 and valine (V), leucine (L) or methionine (M) as the C-terminal residue. The six highest scoring peptides, fulfilling these criteria, were synthesised and analysed for their binding affinity to HLA-A ${ }^{\star} 0201$ by a competition assay using peptide YLLPAIVHI from RNA helicase p72 as positive control and peptide ILK(FITC)EPVHGV from HIV-1 reverse transcriptase as reporter peptide. Binding affinities were classified as strong when the binding of a reporter peptide was inhibited by $75-100 \%$, related to the inhibition of reporter peptide binding by a positive control peptide or as intermediate when the inhibition was $50-$ $75 \%$. The peptides 1472, 1479, 1487, 1494 and 2004 bound with high affinity, whereas peptide 1478 showed an intermediate affinity (Table 3). All six peptides were used for the in vitro stimulation of CD8 + T lymphocytes.

\section{In vitro generation of prostein peptide-specific and tumour-reactive CD8 + cytotoxic effector cells}

$\mathrm{CD} 8+\mathrm{T}$ lymphocytes isolated from the blood of two prostate cancer patients (donors 1 and 3 ) and one healthy donor (donor 2) 
were weekly stimulated with autologous DCs pulsed with a cocktail of the peptides 1478, 1479 and 2004. CD8 + T cells from the same healthy donor (donor 2) and an additional patient (donor 4) were subjected to stimulations with a cocktail of the peptides 1472, 1487 and 1494. After four stimulation cycles, T cells were tested for the presence of peptide-specific CTLs by chromium release assays.

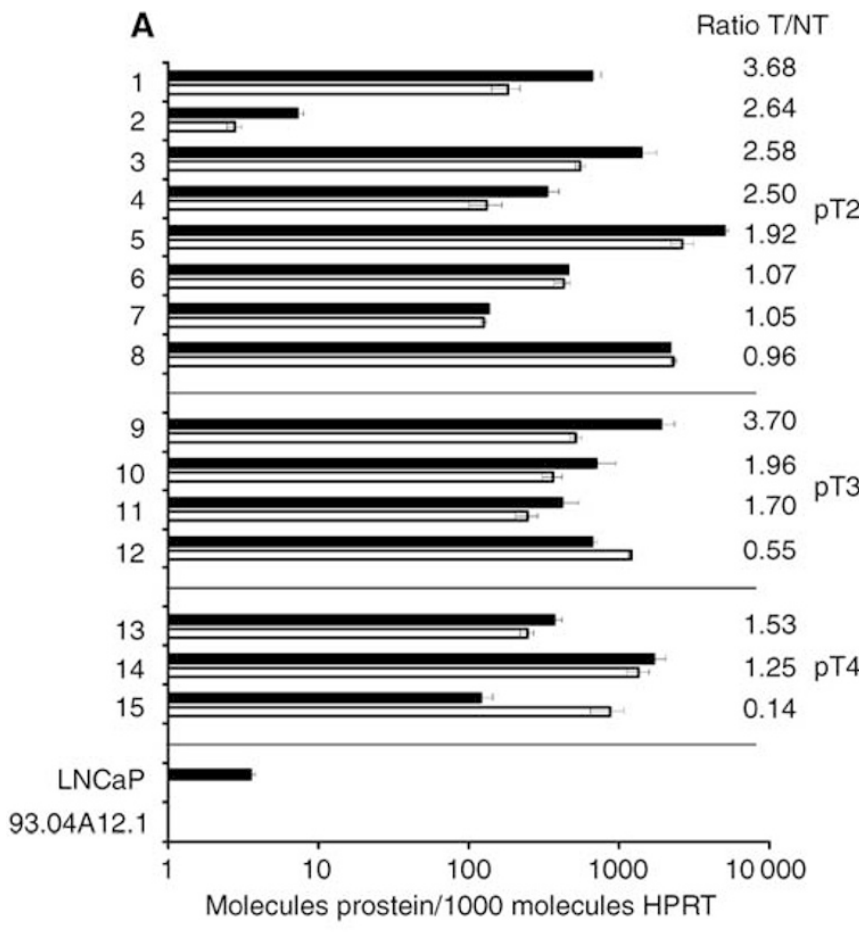

B

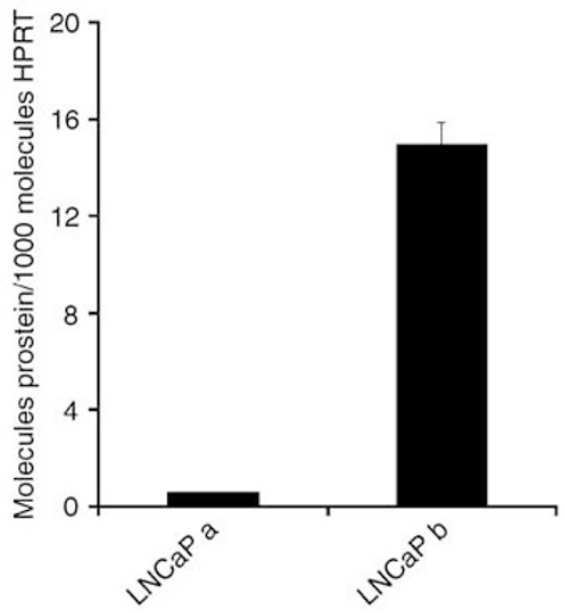

Only peptide 2004 induced specific CTLs in all three donors tested (donors 1-3) as shown by the specific lysis of T2 cells loaded with this peptide (Figure 2). Unloaded T2 cells and T2 cells pulsed with an irrelevant peptide from HIV reverse transcriptase were only marginally lysed (Figure 2). To determine whether peptide 2004 originates from intracellular processing of the prostein protein and is presented on the surface of tumour cells, the peptide-specific $\mathrm{T}$ cells were tested against the prosteinpositive PCa cell line LNCaP 1740. This cell line expresses HLA-A2 molecules at a low density on the cell surface as demonstrated by flow cytometric analysis using the anti-HLA-A2 antibody MA2.1 (Figure 3A). The melanoma cell line 93.04A12.1, which is negative for prostein transcripts (Figure 1A) but expresses HLA-A2 at a much higher level than LNCaP 1740 cells (Figure 3B), was used as a negative control. The T-cell cultures of all three donors effectively lysed LNCaP 1740 cells, whereas only marginal lysis of 93.04A12.1 cells was observed (Figure 4A). Natural killer cell-like activity was excluded by the failure of the peptide 2004-activated T cells to lyse K562 cells (Figure 4A). As illustrated in Figure 4B, the recognition of LNCaP 1740 was restricted to HLA-A2 as shown by a significant reduction of lytic activity in the presence of the anti-HLA-A2 antibody MA2.1.

According to the observation that prostein expression in $\mathrm{LNCaP}$ 1740 cells is regulated by androgens (Figure 1B), we evaluated the cytotoxic activity of the in vitro-generated CD8 + effector T cells against LNCaP 1740 cells that were cultured in the absence or presence of androgen. As depicted in Figure 4C, the T-cellmediated cytotoxicity of all three donors against target cells deprived of androgen was clearly reduced when compared with the lysis of LNCaP 1740 cells grown in the presence of R1881.

\section{DISCUSSION}

Recently, prostein was identified as a novel protein with a unique specificity for normal and malignant prostate tissues as demonstrated by quantitative RT-PCR, Northern blot and cDNA

Figure I Real-time PCR analysis of prostein mRNA expression in matched samples of malignant and nonmalignant prostate tissues, in the PCa cell line LNCaP 1740, and the melanoma cell line 93.04A I2.I. (A) To quantify the prostein mRNA expression in 15 paired cDNA samples of tumourous (black bars) and nontumourous (white bars) prostate tissues and in LNCaP 1740 and 93.04A I2.I cells a 240 bp fragment was amplified in a SYBR Green I-based LC assay. The transcript quantity was normalised to the expression level of HPRT. The results represent the means of two LC runs, bars indicate s.e. The ratio of prostein expression in the tumourous related to the transcript quantity in the corresponding nontumourous tissue sample (ratio T/NT) is given for each tissue pair. Patients' data were classified according to their tumour stage (pT) and within the groups according to the T/NT ratios. (B) The PCa cell line LNCaP 1740 was cultured for $48 \mathrm{~h}$ in the androgen-depleted medium ( $L N C a P a)$ or in the presence of I nM of the synthetic androgen RI88 I ( $L N C a P b$ ) and then used for RNA preparation and quantification of prostein transcripts. The results represent the means of two LC runs, bars indicate s.e.

Table 2 Association of tumour stage and grade with the expression level of prostein mRNA as determined by quantitative RT-PCR

\begin{tabular}{|c|c|c|c|c|c|c|c|}
\hline & \multicolumn{3}{|c|}{ Tumour stage } & \multicolumn{2}{|c|}{ Gleason score } & \multicolumn{2}{|c|}{ Tumour grade } \\
\hline & pT2 $(n=8)$ & pT3 $(n=4)$ & pT4 $(n=3)$ & $\leqslant 7(n=9)$ & $\geqslant 7(n=5)$ & Ila, lib $(n=7)$ & IIIa, IIIb $(n=6)$ \\
\hline
\end{tabular}

aMean value of the individual ratios of transcript quantity in the tumourous samples ( $\mathrm{T}$ ) to that in the corresponding nontumourous tissues (NT) when classified according to pathological stages and grades. $n=$ number of paired tissue samples; RT-PCR = reverse transcription $-P C R$. 


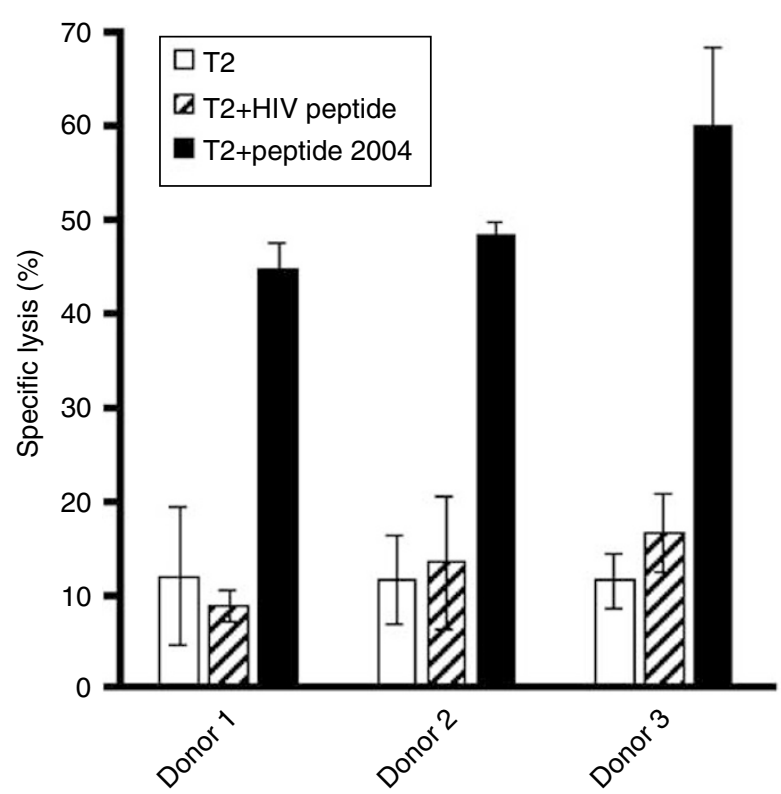

Figure 2 In vitro generation of cytotoxic effector $T$ cells specifically recognising the prostein-derived peptide 2004. Purified CD8 + T lymphocytes of two prostate cancer patients (donors I and 3) and one healthy donor (donor 2) were weekly stimulated by peptide-pulsed autologous DCs. After four stimulations T-cell cultures were tested for the activation of peptide-specific tumour-reactive CTLs. The stimulated T-cell cultures were added to $3 \times 10^{3}$ peptide-pulsed T2 target cells well ${ }^{-1}$ at an effector cell to target cell ratio of 20: I. Unloaded T2 cells and T2 cells pulsed with an irrelevant peptide from HIV reverse transcriptase served as controls. The results represent the mean values of triplicate determinations, bars indicate s.e.

microarray analyses at the transcript level and by immunohistochemical analysis at the protein level (Xu et al, 2001). Whereas Xu et al determined prostein expression in a collection of PCa tissues and normal prostate samples, we expanded this study by using matched pairs of tumourous and nontumourous prostate tissue for the mRNA quantification. Transcripts were abundant in both malignant and nonmalignant prostate tissues. Therefore, prostein like most of the so far described PCa-associated proteins is a tissue-restricted yet not tumour-specific molecule (Hubert et al, 1999; Nelson et al, 1999; Lin et al, 2000; Naz et al, 2002; Herness and $\mathrm{Naz}, 2003)$. When comparing the transript levels of prostein in the malignant tissues with the corresponding nontumourous samples, we found that prostein expression is not reduced in PCa tissues. This is an important prerequisite for molecules that are supposed to serve as a target structure for immunotherapy.

In recent years, HLA allele-specific peptides from a limited number of well-characterised prostate-associated antigens including PSA (Correale et al, 1998), prostate-specific membrane antigen (Tjoa et al, 1996; Horiguchi et al, 2002), prostate acid phosphatase (Peshwa et al, 1998; Inoue et al, 2001) and prostate stem cell antigen (Kiessling et al, 2002) have been identified as target structures of CTLs. These studies have clearly demonstrated that the immune tolerance against self-proteins expressed in normal prostate tissue can be overcome. In addition, clinical PCa responses have been described in vaccination studies based on CD8 + effector T cells targeting different TAAs (Murphy et al, 1999; Small et al, 2000). However, the heterogeneity of individual tumours (Klein et al, 2002) and the diversity of tumour escape mechanisms (Marincola et al, 2000) require the identification of additional target structures for T-cell-based immunotherapy.

The highly prostate-specific expression of prostein suggested extended evaluation of this protein for this form of immunotherapy. To identify CD8 + T-cell epitopes from prostein, six HLA-A ${ }^{\star} 0201$-binding peptides were predicted from the aminoacid sequence of prostein by a computer-based algorithm. For each of the peptides HLA- $A^{\star} 0201$ binding was verified by a competition assay. Of this collection, only peptide 2004 (CLAAGITYV) encompassing the amino-acid residues 31-39 of prostein was able to induce specific CTLs in vitro when tested against peptide-loaded T2 cells. The lack of response to the other five peptides may indicate a low frequency or even absence of $\mathrm{T}$ cells displaying the respective specificities in the repertoire of the tested donors.

The CTLs specifically recognising peptide 2004 on T2 cells were also capable of lysing the HLA-A ${ }^{\star} 0201$-positive and prosteinexpressing PCa cell line LNCaP 1740, demonstrating the autochthonous generation and presentation of this peptide by tumour cells. The prostein specificity and HLA-A2 restriction of LNCaP 1740 cell lysis was supported by different control experiments: (a) neither the natural killer cell-sensitive cell line K562 nor the HLA$\mathrm{A}^{\star} 0201$-positive and prostein-negative melanoma cell line 93.04A12.1 was killed. (b) The lysis of LNCaP 1740 was markedly reduced in the presence of the anti-HLA-A2 antibody MA2.1.

The studies of $\mathrm{Xu}$ et al (2001) have clearly shown for both the transcript and the protein level that prostein is an androgenregulated molecule. Here, we demonstrate that the killing of LNCaP 1740 cells by CTLs specifically recognising peptide 2004 is reduced when the target cells are grown in androgen-deprived medium and can be increased when the medium is supplemented with androgen. This effect can be explained by the androgen-
A

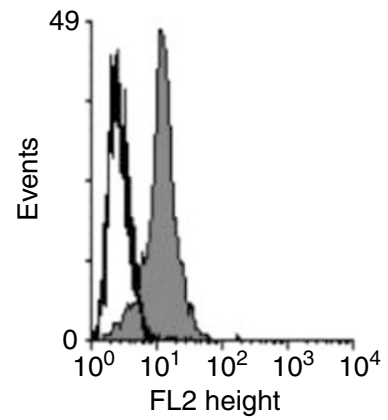

B

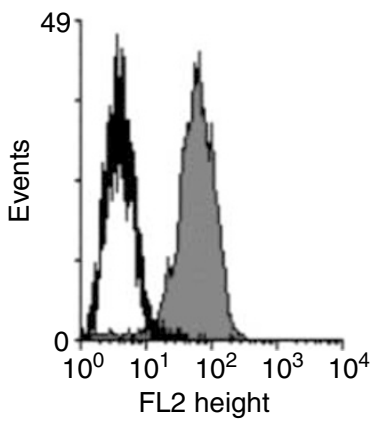

C

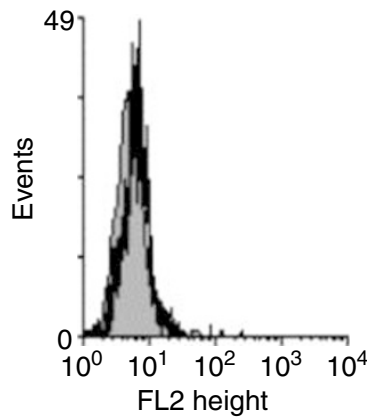

Figure 3 HLA-A2 expression on the surface of the tumour cell lines used as target cells in the chromium release assays. The PCa cell line LNCaP I740 (A), the melanoma cell line 93.04A I2.I (B) and the HLA-A2-negative PCa cell line PC-3 as control (C) were analysed by flow cytometry using the antiHLA-A2 antibody MA2.I as primary antibody and a PE-labelled goat anti-mouse $\lg G\left(a b^{\prime}\right)_{2}$ fragment as secondary antibody. The solid line represents the $|g G|$ isotype control, the shaded peak represents the HLA-A2 staining. 
Table 3 Prediction of HLA-A*020I-restricted prostein-derived peptides and determination of binding affinity by a competition assay

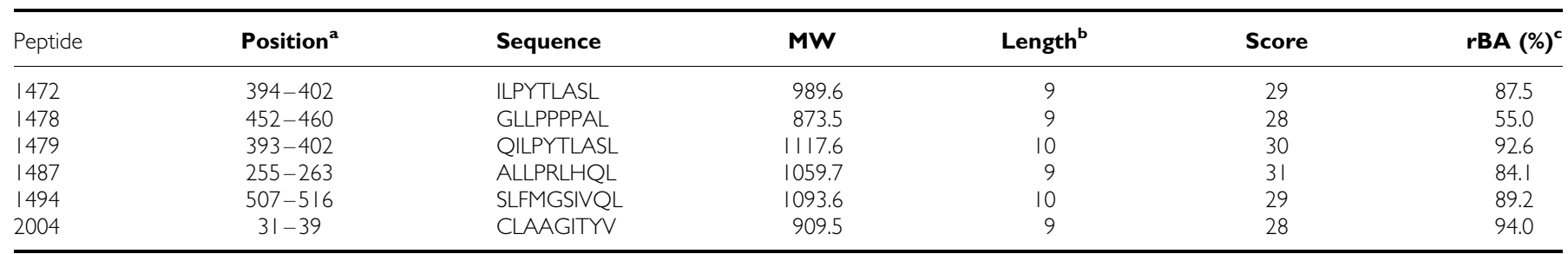

${ }^{a}$ The given numbers indicate the position of the peptide in the amino-acid sequence of prostein (GenBank accession no. NP_I 49093$) .{ }^{b}$ Number of amino acids. ${ }^{\mathrm{C}}$ The relative binding affinities were determined by comparing the inhibition of the reporter peptide binding by the analysed peptides in relation to the inhibition obtained with a positive control peptide which was set as 100\%. The positive control peptide was YLLPAIVHI from RNA helicase p72 and the reporter peptide was ILK(FITC)EPVHGV from HIV-I reverse transcriptase. All peptides were used at a concentration of $10 \mu \mathrm{M}$. rBA, relative-binding affinity; MW, molecular weight; $\mathrm{HLA}=$ human leucocyte antigen.
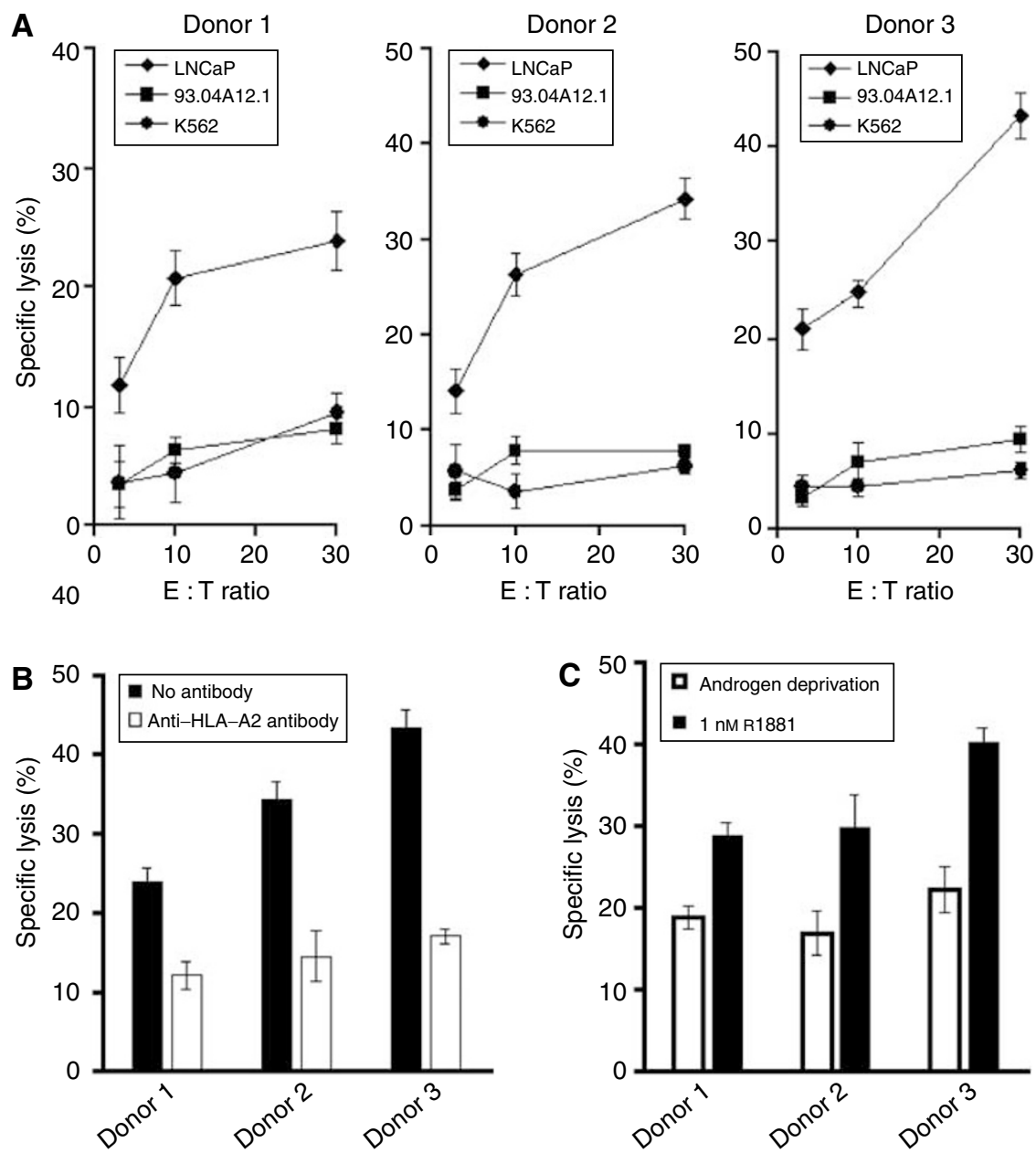

Figure 4 Prostein-specific lysis and HLA-A*020 I-restricted recognition of LNCaP I740 cells by the in vitro-generated cytotoxic effector cells. (A) After four rounds of stimulation activated CD8 + T cells from the three donors were cocultured with $3 \times 10^{3} 51$ Cr-labeled LNCaP I740, 93.04AI2.I or K562 tumour cells well ${ }^{-1}$ at various effector cell (E) to target cell (T) ratios (3: I, I0: I, 30: I). After $4 \mathrm{~h}$ of incubation, chromium release was determined. (B) The inhibition of T-cell-mediated cytotoxicity against LNCaP 1740 cells was tested in the presence of the monoclonal anti-HLA-A2 antibody MA2.I at an E:T ratio of 30: I. (C) Influence of androgen deprivation or supplementation on the prostein-specific lysis of LNCaP I 740 target cells. LNCaP I740 cells were cultured for $24 \mathrm{~h}$ in medium containing charcoal-stipped FCS. Cells were grown for additional $48 \mathrm{~h}$ in the androgen-deprived medium or in the presence of I nM RI88I and then used as target cells in a chromium release assay at an E:T ratio of 30: I. All results represent the mean values of triplicate determinations, bars indicate s.e.

regulated expression level of prostein that may directly influence the density of the respective HLA class I peptide complex on the surface of the LNCaP 1740 cells.

In summary, we identify an HLA-A*0201-restricted CD8 $+\mathrm{T}$ cell epitope derived from the prostate-specific protein prostein that was shown to be widely expressed in PCa. Our results emphasise this protein as a target molecule to be included in immunotherapeutic trials of PCa.

\section{ACKNOWLEDGEMENTS}

We thank B Löbel and K Günther (Institute of Immunology) for excellent technical assistance. We are grateful to Dr K Hölig (Institute of Transfusion Medicine) for the preparation of buffycoats and Dr M Füssel (Institute of Immunology) for HLA typing. This study was supported by the Wilhelm-Sander-Stiftung (1999.009.2) and the Wilhelm-Vaillant-Stiftung. 


\section{REFERENCES}

Bowen C, Bubendorf L, Voeller HJ, Slack R, Willi N, Sauter G, Gasser TC, Koivisto P, Lack EE, Kononen J, Kallioniemi O-P, Gelmann EP (2000) Loss of NKX3.1 expression in human prostate cancers correlates with tumor progression. Cancer Res 60: 6111-6115

Correale P, Walmsley K, Zaremba S, Zhu M, Schlom J, Tsang KY (1998) Generation of human cytolytic $\mathrm{T}$ lymphocyte lines directed against prostate-specific antigen (PSA) employing a PSA oligoepitope peptide. $J$ Immunol 161: $3186-3194$

He WW, Sciavolino PJ, Wing J, Augustus M, Hudson P, Meissner PS, Curtis RT, Shell BK, Bostwick DG, Tindall DJ, Gelmann EP, Abate-Shen C Carter KC (1997) A novel human prostate-specific, androgen-regulated homeobox gene (NKX3.1) that maps to $8 \mathrm{p} 21$, a region frequently deleted in prostate cancer. Genomics 43: $69-77$

Herness EA, Naz RK (2003) A novel human prostate-specific gene-1 (HPG1): molecular cloning, sequencing, and its potential involvement in prostate carcinogenesis. Cancer Res 63: 329-336

Horiguchi Y, Nukaya I, Okazawa K, Kawashima I, Fikes J, Sette A, Tachibana M, Takesako K, Murai M (2002) Screening of HLA-A24restricted epitope peptides from prostate-specific membrane antigen that induce specific antitumor cytotoxic T lymphocytes. Clin Cancer Res 8: $3885-3892$

Howe HL, Wingo PA, Thun MJ, Ries LA, Rosenberg HM, Feigal EG, Edwards BK (2001) Annual report to the nation on the status of cancer (1973 through 1998), featuring cancers with recent increasing trends. $J$ Natl Cancer Inst 93: 824-842

Hubert RS, Vivanco I, Chen E, Rastegar S, Leong K, Mitchell SC, Madraswala R, Zhou Y, Kuo J, Raitano AB, Jakobovits A, Saffran DC, Afar DEH (1999) STEAP: A prostate-specific cell-surface antigen highly expressed in human prostate tumors. Proc Natl Acad Sci USA 96: $14523-14528$

Inoue Y, Takaue Y, Takei M, Kato K, Kanai S, Harada Y, Tobisu K, Noguchi M, Kakizoe $\mathrm{T}$, Itoh K, Wakasugi H (2001) Induction of tumor specific cytotoxic $\mathrm{T}$ lymphocytes in prostate cancer using prostatic acid phosphatase derived HLA-A2402 binding peptide. J Urol 166: $1508-1513$

Kiessling A, Schmitz M, Stevanovic S, Weigle B, Hölig K, Füssel M, Meye A, Wirth MP, Rieber EP (2002) Prostate stem cell antigen: identification of immunogenic peptides and assessment of reactive CD8+ $\mathrm{T}$ cells in prostate cancer patients. Int J Cancer 102: 390-397

Klein CA, Blankenstein TJ, Schmidt-Kittler O, Petronio M, Polzer B, Stoecklein NH, Riethmuller G (2002) Genetic heterogeneity of single disseminated tumour cells in minimal residual cancer. Lancet 360: $683-689$

Lin B, White JT, Ferguson C, Bumgarner R, Friedman C, Trask B, Ellis W, Lange P, Hood L, Nelson PS (2000) PART-1: a novel human prostatespecific, androgen-regulated gene that maps to chromosome $5 \mathrm{q} 12$. Cancer Res 60: 858-863

Marincola FM, Jaffee EM, Hicklin DJ, Ferrone S (2000) Escape of human solid tumors from T-cell recognition: molecular mechanisms and functional significance. Adv Immunol 74: 181-273

Murphy GP, Tjoa BA, Simmons SJ, Jarisch J, Bowes VA, Ragde H, Rogers M, Elgamal A, Kenny GM, Cobb OE, Ireton RC, Troychak MJ, Salgaller ML, Boynton AL (1999) Infusion of dendritic cells pulsed with HLA-A2specific prostate-specific membrane antigen peptides: a phase II prostate cancer vaccine trial involving patients with hormone-refractory metastatic disease. Prostate 38: $73-78$

Naz RK, Santhanam R, Tyagi N (2002) Novel human prostate-specific cDNA: molecular cloning, expression, and immunobiology of the recombinant protein. Biochem Biophys Res Commun 297: 1075-1084

Nelson PS (2002) Identifying immunotherapeutic targets for prostate carcinoma through the analysis of gene expression profiles. Ann NY Acad Sci 975: 232-246

Nelson PS, Gan L, Ferguson C, Moss P, Gelinas R, Hood L, Wang K (1999) Molecular cloning and characterization of prostase, an androgenregulated serine protease with prostate-restricted expression. Proc Natl Acad Sci USA 96: $3114-3119$

Peshwa MV, Shi JD, Ruegg C, Laus R, van Schooten WC (1998) Induction of prostate tumor-specific $\mathrm{CD}^{+}$cytotoxic $\mathrm{T}$-lymphocytes in vitro using antigen-presenting cells pulsed with prostatic acid phosphatase peptide. Prostate 36: $129-138$

Rammensee H-G, Bachmann J, Emmerich NPN, Bachor OA, Stevanovic S (1999) SYFPEITHI: database for MHC ligands and peptide motifs. Immunogenetics 50: $213-219$

Rosenberg SA (1997) Cancer vaccines based on the identification of genes encoding cancer regression antigens. Immunol Today 18: 175-182

Saffran DC, Reiter RE, Jakobovits A, Witte ON (1999) Target antigens for prostate cancer immunotherapy. Cancer Metast Rev 18: 437-449

Schmitz M, Diestelkoetter P, Weigle B, Schmachtenberg F, Stevanovic S, Ockert D, Rammensee H-G, Rieber EP (2000) Generation of survivinspecific CD8+ $\mathrm{T}$ effector cells by dendritic cells pulsed with protein or selected peptides. Cancer Res 60: 4845 - 4849

Sidiropoulus M, Chang A, Jung J, Diamandis EP (2001) Expression and regulation of prostate androgen regulated transcript-1 (PART-1) and identification of differential expression in prostatic cancer. $\mathrm{Br} \mathrm{J}$ Cancer 85: $393-397$

Small EJ, Fratesi P, Reese DM, Strang G, Laus R, Peshwa MV, Valone FH (2000) Immunotherapy of hormone-refractory prostate cancer with antigen-loaded dendritic cells. J Clin Oncol 18: 3894-3903

Tjoa B, Boynton A, Kenny G, Ragde H, Misrock SL, Murphy G (1996) Presentation of prostate tumor antigens by dendritic cells stimulates $\mathrm{T}$ cell proliferation and cytotoxicity. Prostate 28: 65-69

Van der Burg SH, Ras E, Drijfhout JW, Benckhuijsen WE, Bremers AJ, Melief CJ, Kast WM (1995) An HLA class I peptide-binding assay based on competition for binding to class I molecules on intact human B cells. Identification of conserved HIV-1 polymerase peptides binding to HLA$\mathrm{A}^{*} 0301$. Hum Immunol 44: 189-198

Xu J, Kalos M, Stolk JA, Zasloff EJ, Zhang X, Houghton RL, Filho AM, Nolasco M, Badaró R, Reed SG (2001) Identification and characterization of prostein, a novel prostate-specific protein. Cancer Res 61: 1563-1568

Xu LL, Shi Y, Petrovics G, Sun C, Makarem M, Zhang W, Sesterhenn IA, McLeod DG, Sun L, Moul JW, Srivastava S (2003) PMEPA1, an androgenregulated NEDD4-binding protein, exhibits cell growth inhibitory function and decreased expression during prostate cancer progression. Cancer Res 63: 4299-4304

Yousef GM, Obiezu CV, Luo LY, Black MH, Diamandis EP (1999) Prostase/ KLK-L1 is a new member of the human kallikrein gene family, is expressed in prostate and breast tissues, and is hormonally regulated. Cancer Res 59: 4252-4256 